\title{
Moral Distress in Physicians Practicing in Hospitals Affiliated to Medical Sciences Universities
}

\author{
Mahmoud Abbasi ${ }^{1}$; Nasrin Nejadsarvari ${ }^{2,}$; Mehrzad Kiani ${ }^{2}$; Fariba Borhani ${ }^{3}$; Shabnam \\ Bazmi $^{2}$; Saeid Nazari Tavaokkoli ${ }^{4}$; Hamidreza Rasouli ${ }^{5}$ \\ ${ }_{1}^{1}$ Medical Ethics and Law Research Center, Shahid Beheshti University of Medical Sciences, Tehran, IR Iran \\ ${ }^{2}$ Department of Medical Ethics, School of Traditional Medicine, Shahid Beheshti University of Medical Sciences, Tehran, IR Iran \\ ${ }^{3}$ Nursing Ethics Department, Medical Ethics and Law Research Center, Shahid Beheshti University of Medical Sciences, Tehran, IR Iran \\ ${ }_{5}^{4}$ Faculty of Theology, Tehran University, Tehran, IR Iran \\ ${ }^{5}$ Trauma Research Center, Baqiyatallah University of Medical Sciences, Tehran, IR Iran \\ *Corresponding Author: Nasrin Nejadsarvari, Department of Medical Ethics, School of Traditional Medicine, Shahid Beheshti University of Medical Sciences, Tehran, IR Iran. Tel: +98- \\ 9127990798, E-mail: n_nejadsarvari@yahoo.com
}

Received: March 6, 2014; Revised: May 9, 2014; Accepted: June 2, 2014

\begin{abstract}
Background: Researchers have regarded moral distress as a major concern in the health care system. Symptoms associated with moral distress may manifest as frustration, dissatisfaction, and anxiety and may lead to burnout, job leaving, and finally, failure to provide safe and competent care to patients. Proper management of this phenomenon can be fulfilled through study of its causes at different levels of health services and taking necessary measures to solve them.

Objectives: This study aimed to determine the status of moral distress in physicians practicing in hospitals affiliated to Medical Sciences Universities in Tehran.

Materials and Methods: This cross-sectional study was carried out using the Standard Hamric Scale to collect data after modification and evaluation of its reliability and validity. A total of 399 physicians responded to the scale. Data analysis was performed using descriptive and correlation statistics with respect to the variables.

Results: Results showed that the frequency of moral distress of physicians was $1.24 \pm 0.63$ and the intensity of moral distress and composite score of moral distress were $2.14 \pm 0.80$ and $2.94 \pm 2.38$, respectively. A significant negative correlation existed between age and frequency and composite score $(\mathrm{r}=-0.15, \mathrm{P}<0.01$ and $\mathrm{r}=-0.16, \mathrm{P}<0.01$, respectively $)$ as well as years of experience and composite $\operatorname{score}(\mathrm{r}=-0.11, \mathrm{P}=$ 0.04). Moral distress composite score in adults specialists was higher than pediatricians $(\mathrm{P}=0.002)$, but lower in physicians participated in medical ethics training courses compared to those not participated.

Conclusions: Physicians may encounter moral distress during their practice; therefore, the common causes of distress should be identified in order to prevent its occurrence.
\end{abstract}

Keywords:Physicians; Hospitals; Medical Ethics

\section{Background}

In the last three decades, moral distress has been regarded as a growing concern in the health care system and has turned to a focus of research in health care. Researchers and theorists have proven that moral distress has both short- and long-term consequences such as job dissatisfaction of health care providers, burnout, and job leaving (1-10); more importantly, it interferes with safe and competent care to patients (1). Research during the last decade on approaches of ethical action has shown that nurses, physicians, and other care practitioners have frequently referred moral distress as a concern and requested actions in this area (1).

Jameton introduced the term "moral distress" in 1984 (11). He believed that moral distress arises when a nurse cannot perform the action, which is morally correct. Jameton later divided moral distress into two categories of initial and reactive (12). The initial type occurs following institutional constraints or conflict with the values of others appears as feeling hopeless, nervous, and anxious. The reactive type results from inaction to eliminate the initial type and appears as depression, nightmare, and feeling worthless (11-13).

Kalvemark et al. revised Jameton's moral distress definition and defined it as "traditional negative stress symptoms that occur due to situations that involve ethical dimensions and where the healthcare provider feels she/ he is not able to preserve all interests and values at stake" (14). Hence, obviously she focused more on personal and structural factors. In 2000, Webster and Baylis emphasized specifically "personal and perceived constraints," including personal weaknesses that prevent to act in a manner that jeopardizes his/her personal honesty and integrity (15). In 2009, Epstein and Hamric stated that moral residue (i.e. unresolved and reactive moral distress) is more common than was previously thought and may exacerbate in the presence of problematic situations

Copyright (C) 2014, Iranian Red Crescent Medical Journal; Published by Kowsar. This is an open-access article distributed under the terms of the Creative Commons Attribution-NonCommercial 4.0 International License (http://creativecommons.org/licenses/by-nc/4.0/) which permits copy and redistribute the material just in noncommercial usages, provided the original work is properly cited. 
in ward, group, or institution, resulting in the crescendo effect in which moral distress and moral residue increase and ultimately destroy irreversibly individual's ethical integrity (6).

Moral distress arises when clinicians are unable to operate their ethical choices; in other words, they had performed the correct diagnostic moral action but internal and external constraints prevent it to be carried out (12). In these situations, acting against personal and professional values harms individual's reputation and integrity (16). Ethical obligations and commitments cannot be fulfilled, thus the person cannot control his or her judgment and reasoning resulting in error (17).

The complications of psychological imbalance arisen from moral distress may appear as anger, frustration, depression, shame, confusion, sadness, heartbreak, miserable, emptiness (17-20), which may lead to job dissatisfaction, burnout, and job leaving $(2,17,18)$.

Different studies showed that failure to address moral distress, besides affecting physical, mental, and behavioral health of clinicians, impairs health care service $(6,21-23)$. Most national and international research in this field was limited to nursing, while the causes and circumstances of the occurrence of moral distress vary in different professions (7). Only a few countries have carried out surveys on physicians (24-29); while, physicians are always subject to moral distress in the light of factors such as unconscionable act, failure to provide complete treatment because of economic weakness of the patient, ineffective management, lack of time, waiting of patients, lack of resources, ethical dilemmas, and organizational factors (28).

\section{Objectives}

In this study, we examined this problem, specifically in physicians to identify important factors causing moral distress in them in order to help health policy-makers to provide effective solutions for preventing and resolving this problem.

\section{Materials and Methods}

The present cross-sectional study was performed on physicians practicing in hospitals affiliated to all Medical Sciences Universities in Tehran, including Shahid Beheshti, Tehran, Artesh, Baqiyatallah, Azad, Iran, and Shahed from May 2013 to January 2014. We excluded private hospitals. The research was launched after IRB approval (5 Oct 2013, N-153). Among physicians practicing in the mentioned hospitals, 722 were selected through cluster sampling. All doctors in the selected hospitals affiliated to the medical universities in Tehran which accounted for 722 persons. A total of 399 physicians responded to the questionnaire. The formula for sample size was:

$$
n=\frac{z_{1}^{2}-\alpha / 2^{\sigma^{2}}}{d^{2}}
$$

In this formula, the P value of 0.05 was considered significant. Based on the results of Hamric (26) study (on physicians who had experienced moral distress), the mean was 62.58 and the standard deviation was 21.91, and taking $d$ equal to 3. Putting all those numbers in the above equation, the maximum sample size would be 204 . We did not expect all participants to answer to the questionnaire; therefore, all participants were enrolled and finally 399 of them entered the study. The inclusion criteria were recruitment in the hospital, having at least one year of experience, and lack of managerial roles.

The study tool was a questionnaire, including two sections; the first part collected physicians' demographic status and the second was the Standard Hamric Moral Distress Scale-Revised (MDS-R). Demographic information included age, gender, academic level, marital status, specialty, medical experience, and history of medical ethics training courses. To formulate moral distress assessment questionnaire, Professor Corley, the inventor of the first moral distress assessment tool recommended the Standard Harmic Moral Distress Scale-Revised (MDS-R) for adults physicians and pediatricians. Prior to use, an official permission was obtained from Professor Hamric, and the scale was translated into Farsi using forwardbackward method, and then matched. Content validity index (CVI) was used for this study. The scale was sent to 10 medical ethics specialists for validation and after twice validations, it was accepted with an interrater agreement of 0.89 and the required modifications were done as follows; items 17 and 21 were removed, item 9 was modified, and finally items 20, 21, and 22 were added.

The internal consistency coefficient was used for assessing reliability. To this end, the scale was presented to 20 physicians. Cronbach $\alpha$ and test-retest were calculated as $0.92(\mathrm{P}<0.01)$ and 0.86, respectively, (Kendall $t=0.97, \mathrm{P}$ $<0.001$ for 2 consecutive administrations of the scales 1 week apart). The Final version MDS-R included 22 items, with some questions at the end of the scale about intending or attempting to leave clinical position due to moral distress.

The items of MDS-R were categorized according to Likert scale from zero (none) to 4 (largely) to assess the intensity of moral distress and from zero (never) to 4 (often) to assess the frequency of moral distress.

Then, the Likert scale data can be computed into a composite score or actual moral distress using a 2-part procedure. First, the frequency is multiplied by intensity to obtain fxi score, which can range from 0 to 16 , where the items that are less distressing have low fxi scores versus more distressing items, which have higher fxi scores (24). Reporting fxi scores allows you to identify individual items or situations that are distressing. Second, the composite or actual moral distress score is obtained by summing each item's fxi score, resulting in a range of 0 to 336, where less actual distress has low composite score and more actual moral distress has higher composite score (24).

A cover letter accompanied the scale, containing the 
Abbasi M et al.

research objective, voluntary participation, anonymity, and introduction of the researcher and scale provider. Given their tacit consent, the participants were included in the study. Data were collected for three weeks, and only 399 physicians were participated in the study. We had no ceiling and floor effect in our questionnaire.

Two-stage random cluster sampling method was used. In this method, we first referred to the intended university and a few affiliated hospitals were randomly selected. Then, the subjects were selected from these hospitals based on all hired physicians. The required samples included 113 (28.4\%) physicians from Shahid Beheshti University of Medical Sciences, 41 (10.3\%) physicians from Baqiyatallah University of Medical Sciences, 101 (25.4\%) physicians from Tehran University of Medical Sciences, 15 (3.8\%) physicians from Shahed University of Medical Sciences, 77 (19.3\%) physicians from Iran University of Medical Sciences, 21 (5.0\%) physicians from Azad University of Medical Sciences, and 31 (7.8\%) physicians from Army University of Medical Sciences. The selection was based on the population of each above-mentioned universities. After making necessary coordination with the relevant authorities, we referred to each mentioned universities.

Descriptive statistics was used for demographic data. Appropriate correlational (Pearson, Spearman) statistics, based on the variable type (normal or non-normally), were used to examine relationships among variables. Three dependent variables, including moral distress intensity, moral distress frequency, and composite score were assessed separately. In this paper, for measuring questionnaire validity, CVI was used. We did not use analysis of variance (ANOVA) test because of abnormality in some groups and instead, its nonparametric equivalent, the Kruskal-Wallis test, was used.

Quantitative variables were compared between groups using the Studentt test and Kruskal-Wallis and Mann-Whitney $U$ test, depending on whether normal or non-normally distributed variables were used, respectively. We checked all data for a normal distribution using the KolmogorovSmirnov test, and then the data were analyzed using SPSS 20 software (SPSS, Chicago, IL, USA). A P value less than 0.05 were considered statistically significant.

\section{Results}

Out of 722 persons of the sample size, 399 physicians completed the questionnaire; 114 surgeon, 110 internist, 28 anesthesiologist, 38 podiatrist, 14 specialists in emergency medicine, 78 general practitioners, and 17 other specialists. This study had a response rate of $55.2 \%$ and non-response rate of $44.8 \%$. Table 1 depicts demographics of the study sample with respect to the specialty of physicians. The mean \pm SD age of the participants was $40.81 \pm$ $6.63 \mathrm{y}$, and 218 (54.6\%) physicians were male. Mean \pm SD years of experience working as physician was reported as $12.12 \pm 6.64 \mathrm{y}$. A total of 321 (80.5\%) of participants were married and 183 (45.9\%) of them were participated in medical ethics training courses.

We analyzed data and listed the 22 items from the MDSR survey questions in Table 2 with the mean and standard deviation scores of the physicians for intensity, frequency and composite score of moral distress. Mean scores for items on the moral distress intensity score ranged from 0.79 to 3.34, with an overall total mean score of 2.14 (SD 0.80 ). Also, mean \pm SD scores for items on the moral distress frequency and composite scores were $1.24 \pm 0.63$ and $2.94 \pm 2.38$, respectively.

The highest-scoring items for moral distress composite scores belonged to "Witness diminished patient care quality due to poor team communication" (mean \pm SD, $9.26 \pm 6.07$ ). The lowest-scoring item for moral distress composite score was "Increase the dose of sedatives/opiates for an unconscious patient that I believe could hasten the patient's death" (mean \pm SD, $0.19 \pm 0.89$ ).

The mean \pm SD composite score was $60.38 \pm 33.18$ in females and $65.90 \pm 38.78$ in males. The difference of mean composite scores between the female and male was not statistically significant $(P=0.13)$. We found significant negative correlations between the frequency of moral distress and composite moral distress score with age $(\mathrm{r}$ $=-0.15, \mathrm{P}<0.01, \mathrm{r}=-0.16$ and $\mathrm{P}<0.01$, respectively), also no significant correlation was found between the intensity of moral distress and age $(r=-0.03, P=0.72)$. Significant correlation was found between the composite moral distress score and years of experience in their profession $(\mathrm{r}$ $=-0.11, \mathrm{P}=0.04$ ) (Table 3 ). There were no significant correlations between the frequency, or intensity of moral distress score and physician's experience $(\mathrm{r}=-0.09, \mathrm{P}=0.08$; $\mathrm{r}=-0.03, \mathrm{P}=0.5$, respectively). The mean $\pm \mathrm{SD}$ composite score was $62.10 \pm 35.04$ in married physicians and 70.48 \pm 48.20 in single physicians $(\mathrm{P}=0.23)$.

The composite score of physicians with medical ethics training were $58.17 \pm 31.11$, while the composite score in those lacking medical ethics training courses were 69.65 \pm 40.92; a significant difference existed between these two groups $(\mathrm{P}<0.001)$. The composite score of moral distress was statistically higher in adults physicians compared with pediatricians $(\mathrm{P}=0.002)$ (Table 4 ).

Fifteen participants (3.8\%) intended to leave their clinical position (Table 5). The mean of composite score \pm SD in those who recently intended leaving the clinical position was $88.53 \pm 42.41$ and higher than the mean of composite score of the others, i.e. $62.32 \pm 35.56(\mathrm{P}=0.006)$.

The mean of composite score \pm SD of physicians' moral distress with a previous leaving of clinical position due to moral stress was $102.12 \pm 23.99$, which was statistically higher than the mean of composite score \pm SD (55.00 \pm 31.51) of physicians' moral distress who did not intend or act to leave clinical position $(\mathrm{P}<0.001)$. The mean of composite score \pm SD of physicians' moral distress who intended to leave their clinical position but stayed was $87.90 \pm 39.05$; this was statistically more significant than the mean of composite score of physicians neither acted nor intended to leave the clinical position because of 
Abbasi M et al.

moral distress. Statistical analysis showed no significant difference between the mean of composite score of physicians' moral distress who left a clinical position because of moral stress and the mean of composite score of physicians who intended to leave because of moral distress but stayed $(\mathrm{P}=0.710)$ (Table 5$)$.

\begin{tabular}{|c|c|c|c|c|c|c|c|}
\hline Characteristic & Surgeon & Internist & An & $\begin{array}{c}\text { Pediatri- } \\
\text { cian }\end{array}$ & SEM & GP & Others \\
\hline Age, mean $\pm S D, y$ & $41.82 \pm 7.44$ & $41.22 \pm 6.89$ & $41.73 \pm 6.09$ & $42.61 \pm 6.46$ & $37.66 \pm 5.78$ & $38.73 \pm 5.69$ & $37.61 \pm 6.27$ \\
\hline \multicolumn{8}{|l|}{ Gender, No. (\%) } \\
\hline Male & $68.1(77)$ & $52.8(57)$ & $60.7(17)$ & $26.3(10)$ & $78.6(11)$ & $50(39)$ & $47.1(8)$ \\
\hline Female & $31.9(37)$ & $47.2(51)$ & $39.3(11)$ & $73.7(28)$ & $21.4(3)$ & $50(39)$ & $52.9(9)$ \\
\hline Years of Experience, mean \pm SD & $12.74 \pm 7.16$ & $12.02 \pm 7.10$ & $12.84 \pm 6.30$ & $13.82 \pm 6.32$ & $9.63 \pm 4.65$ & $10.85 \pm 5.59$ & $10.00 \pm 4.65$ \\
\hline \multicolumn{8}{|c|}{ Moral training background, No. (\%) } \\
\hline No & $63.6(70)$ & $36.7(40)$ & $55.6(15)$ & $18.4(7)$ & $92.9(13)$ & $41.3(31)$ & $43.8(7)$ \\
\hline Yes & $36.4(40)$ & $63.3(69)$ & $44.4(12)$ & $81.6(31)$ & $7.1(1)$ & $58.7(44)$ & $56.2(9)$ \\
\hline \multicolumn{8}{|l|}{ Marital status, No.(\%) } \\
\hline Married & $89.2(91)$ & $89.4(93)$ & $88.9(24)$ & $94.3(33)$ & $91.7(11)$ & $82.6(57)$ & $80(12)$ \\
\hline Single & $10.8(11)$ & $10.6(11)$ & $11.1(3)$ & $5.7(2)$ & $8.3(1)$ & $69(17.4)$ & $20(3)$ \\
\hline
\end{tabular}

Table 2. The 22 MDS-R Survey Items and Mean Scores of Different Medical Physicians ${ }^{a}$

\begin{tabular}{|c|c|c|c|}
\hline Moral Distress Scale Items & Frequency & Intensity & $\begin{array}{l}\text { Compos- } \\
\text { ite }\end{array}$ \\
\hline $\begin{array}{l}\text { Provide less than optimal care due to pressures from administrators or insurers to reduce } \\
\text { costs. }\end{array}$ & $0.99 \pm 1.17$ & $3.00 \pm 1.48$ & $3.31 \pm 4.37$ \\
\hline Witness healthcare providers giving "false hope" to the patient or family & $1.90 \pm 1.26$ & $0.88 \pm 1.25$ & $1.86 \pm 3.53$ \\
\hline $\begin{array}{l}\text { Follow the family's wishes to continue life support even though I believe it is not in the } \\
\text { best interest of the patient }\end{array}$ & $1.27 \pm 1.13$ & $1.86 \pm 1.12$ & $2.33 \pm 3.08$ \\
\hline Initiate extensive life-saving actions when I think they only prolong death & $1.37 \pm 1.33$ & $1.84 \pm 1.11$ & $2.45 \pm 3.47$ \\
\hline Follow the family's request not to discuss death with a dying patient who asks about dying & $1.29 \pm 1.17$ & $0.88 \pm 1.28$ & $1.15 \pm 2.84$ \\
\hline Feel pressure from others to order what I consider to be unnecessary tests and treatments & $0.70 \pm 1.15$ & $2.24 \pm 1.18$ & $1.77 \pm 3.69$ \\
\hline $\begin{array}{l}\text { Continue to participate in care for a hopelessly ill person who is being sustained on a ven- } \\
\text { tilator, when no one will make a decision to withdraw support }\end{array}$ & $1.44 \pm 1.25$ & $2.06 \pm 1.09$ & $3.05 \pm 3.49$ \\
\hline $\begin{array}{l}\text { Avoid taking action when I learn that a physician or nurse colleague has made a medical } \\
\text { error and does not report it }\end{array}$ & $0.77 \pm 1.14$ & $2.93 \pm 1.12$ & $2.15 \pm 3.60$ \\
\hline $\begin{array}{l}\text { Assist physician or other health care providers who in my opinion are not as competent as } \\
\text { the patient care requires }\end{array}$ & $1.43 \pm 1.17$ & $2.42 \pm 1.11$ & $3.28 \pm 3.06$ \\
\hline Be required to care for patients I do not feel qualified to care for & $1.34 \pm 1.04$ & $1.99 \pm 1.04$ & $2.72 \pm 2.82$ \\
\hline Let medical students perform painful procedures on patients solely to improve their skill & $1.27 \pm 1.13$ & $2.12 \pm 1.09$ & $2.67 \pm 2.98$ \\
\hline $\begin{array}{l}\text { Provide care that does not relieve the patient's suffering because I fear that increasing the } \\
\text { dose of pain medication will cause death }\end{array}$ & $1.02 \pm 1.05$ & $0.79 \pm 1.28$ & $0.94 \pm 2.59$ \\
\hline Request nurses or others not to discuss the patient's prognosis with the patient or family & $0.72 \pm 0.87$ & $1.50 \pm 1.10$ & $0.98 \pm 1.57$ \\
\hline $\begin{array}{l}\text { Increase the dose of sedatives/opiates for an unconscious patient that I believe could has- } \\
\text { ten the patient's death }\end{array}$ & $0.10 \pm 0.43$ & $2.44 \pm 1.36$ & $0.19 \pm 0.8$ \\
\hline $\begin{array}{l}\text { Take no action about an observed ethical issue because the involved staff member or } \\
\text { someone in a position of authority requested that I do nothing }\end{array}$ & $1.08 \pm 1.08$ & $2.30 \pm 1.38$ & $2.39 \pm 2.88$ \\
\hline $\begin{array}{l}\text { Follow the family's wishes of the patient's care when I do not agree with them, but do so } \\
\text { because of fears of a lawsuit }\end{array}$ & $0.60 \pm 0.90$ & $1.98 \pm 1.36$ & $1.23 \pm 2.57$ \\
\hline Witness diminished patient care quality due to poor team communication & $2.61 \pm 1.45$ & $3.33 \pm 1.12$ & $9.26 \pm 6.07$ \\
\hline $\begin{array}{l}\text { Ignore situations in which patients have not been given adequate information to insure } \\
\text { informed consent }\end{array}$ & $0.29 \pm 0.73$ & $0.85 \pm 1.33$ & $0.32 \pm 1.27$ \\
\hline Watch patient care suffer because of a lack of provider continuity & $1.32 \pm 1.02$ & $2.62 \pm 1.13$ & $3.66 \pm 3.48$ \\
\hline $\begin{array}{l}\text { Because of insufficient time, I cannot admit patient and provide complete and appropri- } \\
\text { ate treatment }\end{array}$ & $2.19 \pm 1.58$ & $2.55 \pm 1.26$ & $5.79 \pm 4.95$ \\
\hline $\begin{array}{l}\text { Because of shortage of drugs and medical equipment, I could not provide the appropriate } \\
\text { treatment for the patient }\end{array}$ & $2.55 \pm 1.46$ & $3.32 \pm 1.16$ & $8.94 \pm 6.06$ \\
\hline I do not give the right treatment to the patient because he cannot pay the hospital costs & $1.21 \pm 1.34$ & $3.34 \pm 1.25$ & $4.19 \pm 4.97$ \\
\hline
\end{tabular}

$\frac{\text { I do not give the right treatment to th }}{\mathrm{a} \text { All of the values are presented as Mean } \pm \text { SD. }}$ 
Abbasi M et al.

\begin{tabular}{lccc}
\hline Table 3. Correlation Between Variables & & & \\
\hline Items & Frequency & Intensity & Composite \\
\hline Age & $-0.15^{\mathrm{a}}$ & 0.03 & $-0.16^{\mathrm{a}}$ \\
Years of experience & -0.09 & -0.03 & $-0.11^{\mathrm{b}}$ \\
\hline $\begin{array}{l}\mathrm{a} \text { P value is less than } 0.01 . \\
\mathrm{b} \text { P value is less than 0.05. }\end{array}$ & & \\
& & & \\
\hline Table 4. Mean (SD) Composite Moral Distress Score of Physicians Respect to Specialty a,b & Intensity & Composite \\
\hline Items & Frequency & $38.55 \pm 16.56,37(2-83)$ & $64.14 \pm 37.81,66(0-201)$ \\
\hline Surgeons & $30.07 \pm 37.81,31.5(0-60)$ & $54.74 \pm 14.57,54(9-88)$ & $69.89 \pm 37.30,64(0-229)$ \\
Internists & $24.87 \pm 10.51,23(0-63)$ & $40.33 \pm 16.53,40(16-88)$ & $61.14 \pm 40.38,66(0-144)$ \\
Anesthesiologist & $32.42 \pm 18.28,38(0-58)$ & $55.42 \pm 23.31,59(0-88)$ & $43.47 \pm 27.31,38(0-93)$ \\
Pediatricians & $16.05(7.35), 17(0-32)$ & $36.71 \pm 5.16,37(28-48)$ & $89.71 \pm 13.00,85.5(72-124)$ \\
Specialist in Emergency Medicine & $51.37 \pm 2.92,52(46-56)$ & $43.54 \pm 15.95,44(0-70)$ & $61.87 \pm 34.48,60.5(0-175)$ \\
General Physician & $27.08 \pm 13.51,25(0-56)$ & $51.88 \pm 13.66,54(18-80)$ & $47.76 \pm 25.35,42(0-111)$ \\
Other specialists & $18.52 \pm 8.06,17(0-32)$ & $<0.001$ & $<0.001$ \\
\hline P value & $<0.001$ & &
\end{tabular}

${ }^{\mathrm{a}}$ Kruskal-Wallis test used for comparison between groups.

$\mathrm{b}$ Data are presented as Mean \pm SD, Median (Min-Max).

Table 5. Intentions to Leave the Profession With Mean MDS-R Scores

\begin{tabular}{lccc}
\hline Variables & No. $(\%)$ & Mean \pm SD, Median (Min-Max) & P Value \\
\hline No, I've never considered quitting or left a position & $75(299)$ & $55.00 \pm 31.51^{\mathrm{a}}, 58(0-229)$ & \\
Yes, I considered quitting but did not leave & $22.5(90)$ & $87.90 \pm 39.05,87(9-201)$ & $<0.001^{\mathrm{b}}$ \\
Yes, I left a position & $2.5(10)$ & $102.12 \pm 23.99,97(87-134)$ & \\
Not considering leaving now & $96.2(384)$ & $62.32 \pm 35.56,64(0-229)$ & $0.006^{\mathrm{a}}$ \\
Considering leaving now & $3.8(15)$ & $88.53 \pm 42.41,98(18-176)$ & \\
\hline
\end{tabular}

a P value less than 0.001, significant respect to others groups using Mann-Whitney U test.

b Kruskal-Wallis test used for comparison between groups.

\section{Discussion}

Although most studies on moral distress emphasize the problem in nurses, our study on Iranian physicians showed a moderate level of moral distress among them. This finding is consistent with the result of Wiggleton et al. (27) and Hamric et al. (26) who found that moral distress arises not only in nurses but also in physicians; although physicians showed lower levels of moral distress, the majority of clinical situations leading to moral distress were the same in both groups.

The mean of composite score of moral distress in our study had no significant difference between two sexes. Forde et al. (29) found that female Norwegian physicians are more affected by moral distress than their male partners. In Wiggleton's study (27), men showed more distress than women, although women were significantly more faced with potentially distressing situations.

According to this study, pediatricians and emergency specialists showed the minimum and maximum mean of composite score of moral distress, respectively (Table
2). Interestingly, the lowest moral distress frequency and the highest moral distress intensity were seen in pediatrics wards, while the highest moral distress frequency and lowest moral distress intensity were seen in emergency wards. No similar study was found assessing moral distress in specialty-separated physicians. In other words, particular conditions of emergency patients and urgency of the therapeutic measures may underlie moral distress in emergency units. This indicates that moral distress is not merely the result of internal constraints such as self-doubt, lack of confidence, fear, and anxiety; rather external constraints are involved such as intersectoral policies, legal and financial constraints, as well as communications between treatment team members. To put it another way, difference in the moral atmosphere of different wards is an important factor for frequency and intensity of moral distress; the more positive perception of individual from moral atmosphere, less moral distress level develops $(27,30,31)$. 
Our study showed that the highest mean of composite score of moral distress in all categories of Table 3 is related to the items "Witness diminished patient-care quality due to poor team communication" and "Due to the shortage of drugs and medical equipment, I could not provide the appropriate treatment to the patient," respectively (Table 2). Besides stressfulness of these two factors (weak teamwork of clinicians and unfair resources allocation), they indicate a high sense of personal responsibility in the studied physicians, because they were affected by moral distress when observing failure to provide quality care to patients owning to lack of teamwork or inability to provide adequate treatment to patients because of lack of resources. The studies of Iglesias et al. (28) in physicians and Browning (32) and Pauly (13) in nurses showed similar results. However, in some other studies, items associated with the provision and continuation of "futile treatment and not in patients' best interest" created the highest level of moral distress (33-39).

In our study, high mean of composite scores of moral distress in physicians who had not participated in ethics training courses compared with those participated, indicated the effective role of training in moral distress reduction. We found that traditional medical ethics education, which is academically provided during general medicine education and only emphasizes the principles and ethical dilemmas, is not sufficient to address moral distress. Therefore, holding medical ethics training courses, which familiarize medical staff with predisposing social, institutional, and legal factors of moral distress seems necessary. On the other hand, according to Jameton's definition, the key component in the creation of moral distress is inability to perform the action, which is morally acceptable to person; thus psychological empowerment or promotion of person's ability to practice his or her faith will have an important role in reducing moral distress. Since education can improve psychological empowerment, it can reduce moral distress (12). In addition, other studies have shown that positive perception of ethical atmosphere is an effective step in reducing moral distress and training makes it happen $(40,41)$.

A significant negative relationship was found between age and frequency and the composite score of moral distress, while, there was no significant relationship between age and intensity of moral distress. Perhaps this can be attributed to age-related desensitization to person's surrounding. Elpern also found the similar results (34). While Corley et al. reported a negative correlation between age and the level of moral distress (42).

According to the results, despite a weak negative relationship between years of experience and the combined score of moral distress, no relationship was found between years of experience and the frequency and intensity of moral distress. Also, Allen et al. (24) did not find a relationship between work experience and moral distress level. This result showed that moral distress is a personal experience rather than a situational experience. Because individual's perception of obligations varies, perhaps some designed items in our assessment were not very consistent with specialties.

Regarding strong points of our study, this research was done for the first time in our country. It evaluated moral distress between different medical specialists in several universities in a large city, and it helped to recognize moral distress among different physicians, and finally the results may help the healthcare policy makers improve the ethical problems in the medical community. This study could form the basis for further quantitative and qualitative research in the field of medical ethics to establish the moral distress. Most previous studies of moral distress studied nurses as their subjects and physicians were ignored. With regard to limitation of this research, although the response rate was not high in this survey, this study had a response rate of $55.2 \%$, and compared with similar articles, this figure is very good. Another problem of this research is to obtain the hospital authorities' approval to distribute the questionnaires. Of course each hospital had its own rules, but with frequent follow-up by the project manager, these obstacles were resolved.

Our results showed that physicians who intended to leave their clinical position had experienced more moral distress than others. Similarly, those who had left the position were more affected by moral distress than those neither intended nor left the clinical position. This result is consistent with the results of Allen et al.(24).

In addition to great financial and professional costs, leaving the clinical position dissatisfies patient and ultimately, creates problems for organization and community (43). Research shows the relationship between moral distress and burnout (44) which is a cause of job leaving (44).

There was a moderate amount of moral distress in the studied physicians. According to the results of this study, one can claim that the medical ethics course provided academically during medical education is not adequate to reduce moral stress and training courses of medical ethics proportional to profession seems necessary. This can enhance individuals' moral reasoning and their perception level of ethical atmosphere, and then reduce their moral distress level and its acute complications such as burnout and leaving the profession. It should be noted that leaving clinical position and profession not only affects national economy and creates turmoil in organization and ultimately in the community, but also and more importantly causes failure to provide competent treatment to patients. Therefore, health policy makers should try to reduce moral distress through proper planning.

According to common causes of moral distress, it is necessary that the health sector appropriately allocate resources by adopting required measures and prioritizing community health needs in order to prevent moral distress in therapists who provide appropriate treatment for the patients. In addition, holding training-practical 
workshops can improve communication skills among members of the treatment team. With respect to the items causing moral distress in this study, interventional studies can be attempted in this field, which its results may be used to propose practical solutions to resolve moral distress.

\section{Acknowledgements}

This article is a part of Ph.D. thesis of Dr. Nasrin Nejadsarvari at the School of Traditional Medicine, Shahid Beheshti University of Medical Sciences. The authors would like to express their appreciation to all the physicians practicing in the hospitals of Imam khomeini, Rasoul Akram, Valiasr, Institute of Cancer, Taleghani, Modaress, Mostafa khomeini, Imam Reza, Baqiyatallah Javaheri, who participated in this study.

\section{Authors' Contributions}

Study concept and design, acquisition of data, drafting of the manuscript, and critical revision of the manuscript for important intellectual content: Nasrin Nejadsarvari; Statistical analysis, analysis and interpretation of data: Hamidreza Rasouli; Administrative, technical, and material support: Fariba Borhani; and Study supervision: Mahmoud Abbasi, Mehrzad Kiani.

\section{References}

1. Pauly BM, Varcoe C, Storch J. Framing the issues: moral distress in health care. HEC Forum. 2012;24(1):1-11.

2. Corley MC, Elswick RK, Gorman M, Clor T. Development and evaluation of a moral distress scale. JAdv Nurs. 2001;33(2):250-6.

3. Edward KL, Hercelinskyj G. Burnout in the caring nurse: learning resilient behaviours. BrJ Nurs. 2007;16(4):240-2.

4. Schwenzer KJ, Wang L. Assessing moral distress in respiratory care practitioners. Crit Care Med. 2006;34(12):2967-73.

5. Winland-Brown JE, Dobrin A. A comparison of physicians'and nurses' responses to selected ethical dilemmas. Forum Pub Polic J. 2009;1Y19.

6. Epstein EG, Hamric AB. Moral distress, moral residue, and the crescendo effect. JClin Ethics. 2009;20(4):330-42.

7. Epstein EG, Delgado S. Understanding and addressing moral distress. Online J Issues Nurs . 2010;15(3).

8. Openshaw L. Moral distress and the need for moral courage in social work practice. Presented at: North American Association of Christians in Social Work Convention.PA: Pittsburgh; 2011.

9. Maslach C. Engagement research: some thoughts from a burnout perspective. Eur JWork Organ Psychol. 2011;20(47Y52).

10. Epp K. Burnout in critical care nurses: a literature review. Dynamics. 2012;23(4):25-31.

11. Jameton A, Jackson EM. Nuclear war and nursing ethics. What is the nurse's responsibility? Mobius. 1984;4(1):75-88.

12. Jameton A. Dilemmas of moral distress: moral responsibility and nursing practice. AWHONNS Clin Issues Perinat Womens Health Nurs. 1993;4(4):542-51.

13. Pauly B, Varcoe C, Storch J, Newton L. Registered nurses' perceptions of moral distress and ethical climate. Nurs Ethics. 2009;16(5):561-73.

14. Kalvemark S, Hoglund AT, Hansson MG, Westerholm P, Arnetz B. Living with conflicts-ethical dilemmas and moral distress in the health care system. Soc Sci Med. 2004;58(6):1075-84.

15. Webster G, Bayliss F, Rubin S, Zoloth L. Moral Residue. Margin of Error: The Ethics of Mistakes in the Practice of Medicine. Hagerstown: MdUniversity Publishing Group; 2000.
16. Rushton $\mathrm{CH}$. Defining and addressing moral distress: tools for critical care nursing leaders. AACN Adv Crit Care. 2006;17(2):161-8.

17. Corley MC. Nurse moral distress: a proposed theory and research agenda. Nurs Ethics. 2002;9(6):636-50.

18. Corley MC. Ethical dimensions of nurse-physician relations in critical care. Nurs Clin North Am.1998;33(2):325-37.

19. Rodney P. Moral distress in critical care nursing. Can Crit Care Nurs J.1988;5(2):9-11.

20. Peter E, Liaschenko J. Perils of proximity: a spatiotemporal analysis of moral distress and moral ambiguity. Nurs Inq. 2004;11(4):218-25.

21. Catlin A, Armigo C, Volat D, Vale E, Hadley MA, Gong W, et al. Conscientious objection: a potential neonatal nursing response to care orders that cause suffering at the end of life? Study of a concept. Neonatal Netw. 2008;27(2):101-8.

22. Shepard A. Moral distress: a consequence of caring. Clin J Oncol Nurs. 2010;14(1):25-7.

23. Wiegand DL, Funk M. Consequences of clinical situations that cause critical care nurses to experience moral distress. Nurs Ethics. 2012;19(4):479-87.

24. Allen R, Judkins-Cohn T, deVelasco R, Forges E, Lee R, Clark L, et al. Moral distress among healthcare professionals at a health system. JONAS Healthc Law Ethics Regul. 2013;15(3):111-8.

25. Brazil K, Kassalainen S, Ploeg J, Marshall D. Moral distress experienced by health care professionals who provide home-based palliative care. Soc Sci Med. 2010;71(9):1687-91.

26. Hamric AB, Borchers CT, Epstein EG. Development and testing of an instrument to measuremoral distress in healthcare professionals. AJOB Prim Res. 2012;3(2):1Y9.

27. Wiggleton C, Petrusa E, Loomis K, Tarpley J, Tarpley M, O'Gorman ML, et al. Medical students' experiences of moral distress: development of a web-based survey. Acad Med. 2010;85(1):111-7.

28. Losa Iglesias ME, Becerro de Bengoa Vallejo R, Fuentes PS, Trepal MJ. Comparative analysis of moral distress and values of the work organization between American and Spanish podiatric physicians. JAm Podiatr Med Assoc. 2012;102(1):57-63.

29. Forde R, Aasland OG. Moral distress among Norwegian doctors. J Med Ethics. 2008;34(7):521-5.

30. Silen M, Svantesson M, Kjellstrom S, Sidenvall B, Christensson L. Moral distress and ethical climate in a Swedish nursing context: perceptions and instrument usability. J Clin Nurs. 2011;20(2324):3483-93.

31. Lutzen K, Kvist BE. Moral distress: a comparative analysis of theoretical understandings and inter-related concepts. HEC Forum. 2012;24(1):13-25.

32. Browning AM. CNE article: moral distress and psychological empowerment in critical care nurses caring for adults at end of life. Am J Crit Care. 2013;22(2):143-51.

33. Meltzer LS, Huckabay LM. Critical care nurses' perceptions of futile care and its effect on burnout. Am JCrit Care. 2004;13(3):202-8.

34. Elpern EH, Covert B, Kleinpell R. Moral distress of staff nurses in a medical intensive care unit. Am J Crit Care. 2005;14(6):523-30.

35. Mobley MJ, Rady MY, Verheijde JL, Patel B, Larson JS. The relationship between moral distress and perception of futile care in the critical care unit. Intensive Crit Care Nurs. 2007;23(5):256-63.

36. Hamric AB, Blackhall LJ. Nurse-physician perspectives on the care of dying patients in intensive care units: collaboration, moral distress, and ethical climate. Crit Care Med. 2007;35(2):422-9.

37. Corley MC. Moral distress of critical care nurses. Am J Crit Care. 1995;4(4):280-5.

38. Wilkinson JM. Moral distress in nursing practice: experience and effect. Nurs Forum. 1987;23(1):16-29.

39. McClendon H, Buckner EB. Distressing situations in the intensive care unit: a descriptive study of nurses' responses. Dimens Crit Care Nurs. 2007;26(5):199-206.

40. Luthar H, DiBattista R, autschi T. Perception of What the Ethical Climate is and What it Should be: The Role of Gender, Academic Status, and Ethical Education. .J Busines Eth.1997;16(2):205-17.

41. Goldman A, Tabak N. Perception of ethical climate and its relationship to nurses' demographic characteristics and job satisfaction. Nurs Ethics. 2010;17(2):233-46.

42. Corley MC, Minick P, Elswick RK, Jacobs M. Nurse moral distress 
and ethical work environment. Nurs Ethics. 2005;12(4):381-90.

43. Misra-Hebert AD, Kay R, Stoller JK. A review of physician turnover: rates, causes, and consequences. AmJMed Qual.2004;19(2):56-66.
44. Cavaliere TA, Daly B, Dowling D, Montgomery K. Moral distress in neonatal intensive care unit RNs. Adv Neonatal Care. 2010;10(3):145-56 